\title{
Couf $-910981-.59$
}

WSRC-MS- -91-096

DE92 008842

\section{EVALUATION OF A RAPID HEADSPACE ANALYSIS METHOD FOR ANALYSIS OF VOLATILE CONSTITUENTS IN SOILS AND SEDIMENTS (U)}

by

W. R. Sims, B. B. Looney, and C. A. Eddy

Westinghouse Savannah River Company

Savannah River Site

Aiken, South Carolina 29808

A paper proposed for presentation and publication

DOE Environmental Restoration 191 Seminor

Pasco, Washington

September $10-12,1991$

This paper was prepared in connection with work done under Contract No. DE-AC09-89SR18035 with the U.S. Department of Energy. By acceptance of this paper, the publisher and/or recipient acknowledges the U.S. Government's right to retain a nonexclusive, royalty-free license in and to any copyright covering this paper, along with the right to reproduce and to authorize others to reproduce all or part of the copyrighted paper.

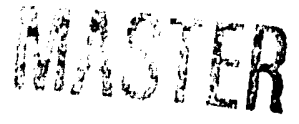




\title{
EVALUATION OF A RAPID HEADSPACE ANALYSIS METHOD FOR ANALYSIS OF VOLATILE CONSTITUENTS IN SOILS AND SEDIMENTS
}

\author{
W. R. Sims, B. B. Looney, and C. A. Eddy \\ Westinghouse Savannah River Company \\ Savannah River Site \\ Aiken, SC 29808
}

\begin{abstract}
Contamination of the subsurface by volatile organic solvents is a common and significant environmental problem. A critical component of developing an accurate assessment of a site contaminated by these solvents is the acquisition of closely spaced, high quality contaminant concentration data. Many volatile organics are relatively mobile in the subsurface, requiring characterization of both horizontal and vertical contaminant migration. The volatile nature of these analytes, combined with the cost and effort typically required to perform quantitative analysis, has often compromised the number and quality of analyses used in characterization studies. A headspace analysis method was developed by Savannah River Laboratory to facilitate accurate and rapid delineation of the vertical and horizontal extent of volatile organic contamination in the subsurface. The method was designed to reduce sample handling, laboratory preparation, and analytical complexity. The headspace analysis method consists of four steps: 1) subsample the split spoon core immediately after opening the barrel using a small tube/plunger system, 2) place the subsample into a $22.5 \mathrm{~mL}$ headspace vial, 3 ) add $5 \mathrm{~mL}$ of distilled water and cap with a teflon lined septum, and 4) analyze on a gas chromatograph. This method was developed and modified as a result of multiple site investigations and has been applied to over 1500 samples.
\end{abstract}

To evaluate the headspace analysis method, we collected over 100 samples from four borings at depths ranging from 5 to 140 feet. Samples were analyzed using the headspace method and the results were compared to adjacent samples analyzed onsite using EPA methods that were modified to minimize losses of volatile constituents. The modified EPA method consisted of pentane extraction in a sealed vial after collection, weighing, and transfer in an onsite laboratory. The comparison analyses were performed by an independent organization. Despite the precautions incorporated into the modified EPA method, the analytical results indicate that sample transfers in the field and laboratory resulted in volatilization of most of the volatile solvents in the sediment samples. The headspace method appears to provide more representative data on the samples. One limitation of the headspace method is that the sample can not be diluted; thus, very high concentrations are truncated by an upper limit of detection. In most cases, this truncation may not be of practical significance because it occurs at relatively high concentrations (e.g., $100,000 \mathrm{ng} / \mathrm{g}$ ). The results indicate that the headspace method minimized loss of volatiles associated with sample handling and provided large amounts of closely spaced data in a cost effective manner. The headspace results can be generated rapidly and transferred to the field such that informed decisions can be made during site characterization.

The information contained in this article was developed during the course of work under Contract No. DE-AC09. 89SR18035 with the U. S. Department of Energy. By acceptance of this paper, the publisher and/or recipient acknowledges the U. S. Governments right to retain a nonexclusive, royalty-free license in and to any copyright covering this paper along with the right to reproduce, and to authorize others to reproduce all or part of the copyrighted paper. 


\section{INTRODUCTION}

Detection and delineation of volatile organic solvent contamination at a hazardous waste site can be a complex problem. The number and quality of analyses used in characterization studies has often been compromised by the difficulties and costs associated with quantitative analysis of these volatile analytes. A headspace analysis method was developed by the Westinghouse Savannah River Laboratory to facilitate the accurate and rapid delineation of the vertical and horizontal extent of volatile organic contamination in the subsurface, and to reduce the sample handling, laboratory preparation, and analytical complexity generally associated with the use of several United States Environmental Protection Agency Analysis Methods.

To evaluate the headspace method, over 100 subsurface sediment samples were collected from 4 sediment borings drilled at the Savannah River Site (Figure 1). The sediment samples were analyzed using the headspace method and the results were compared to adjacent samples collected and analyzed by an independent subcontractor. The subcontractor used EPA methods that were modified to minimize losses of volatile constituents. A comparative study of the sample collection procedures, laboratory procedures, and analytical results of the headspace method and the subcontractor modified EPA method is presented in this paper.

\section{SAMPLING AND ANALYTICAL METHODS}

\section{Sample Collection Procedure}

The sediment borings were drilled at four sites adjacent to a solvent tank farm located west of a fuel and target tube manufacturing facility in M-Area at the Savannah River Site (Figure 2). The boring locations were selected based on results from a shallow soil gas survey and a documented solvent spill. In October 1975, over 1200 gallons of tetrachloroethylene (PCE) leaked from a cracked ceramic pump seal connected to one of the solvent tanks. The solvents were used during the late 1950's to the early 1980's to degrease the fuel and target tubes prior to shipment to the nuclear reactors.

The sediment borings were drilled with a Speedstar Quickdrill 275 utilizing 4-1/4-inch inside diameter hollow-stem augers. A standard 2-inch inside diameter split-spoon sampler was advanced vertically according to Standard Penetration Test procedures (ASTM D1586) at five foot intervals, beginning immediately below ground surface to a depth of approximately 140 feet or top of the water table. After each advance, the split spoon sampler was opened and two adjacent samples of sediment were collected. One sediment sample was collected for headspace analysis and the other collected by an independent subcontractor for analysis by a modified EPA Method. The remaining sediment left in the split-spoon was field screened with an HNu photoionization organic vapor meter and a Ludlum G.M. radiation detector and visually classified.

\section{Headspace Sampling Procedure}

The headspace sediment subsample (3-5 grams) was collected inmediately from the open spilt-spoon using an open-ended plastic disposable syringe and extruded into a $22.5 \mathrm{~mL}$ borosilicate vial. Five mL of distilled water were added to the subsample using a pipet and the vial was sealed by crimping an aluminium cap around a teflon-lined butyl rubber septum. The sample vial was labeled and placed in an ice chest cooled to approximately $4^{\circ}$ 


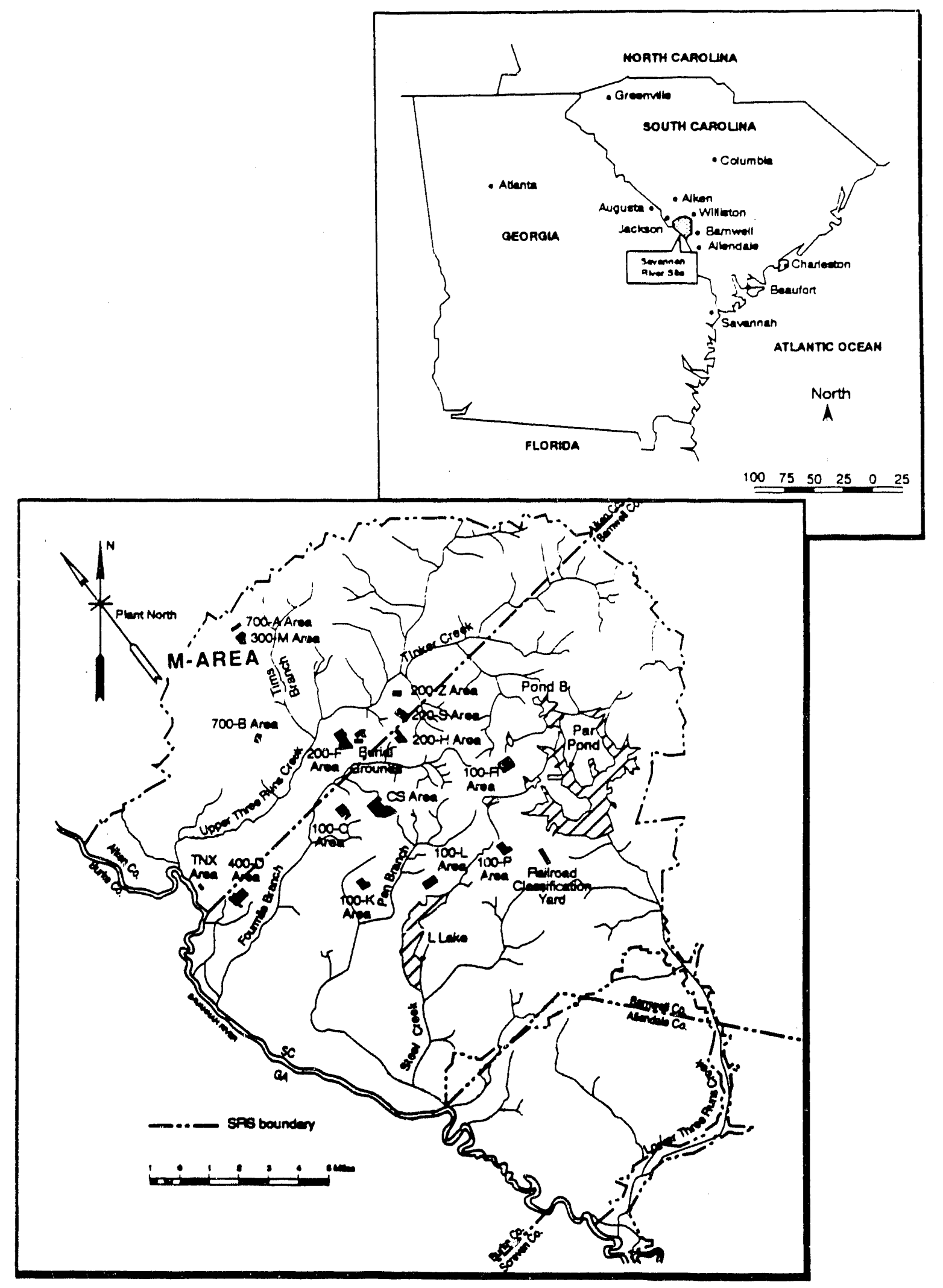

Figure 1. Map showing the location of the solvent spill site at the Savannah River Site 


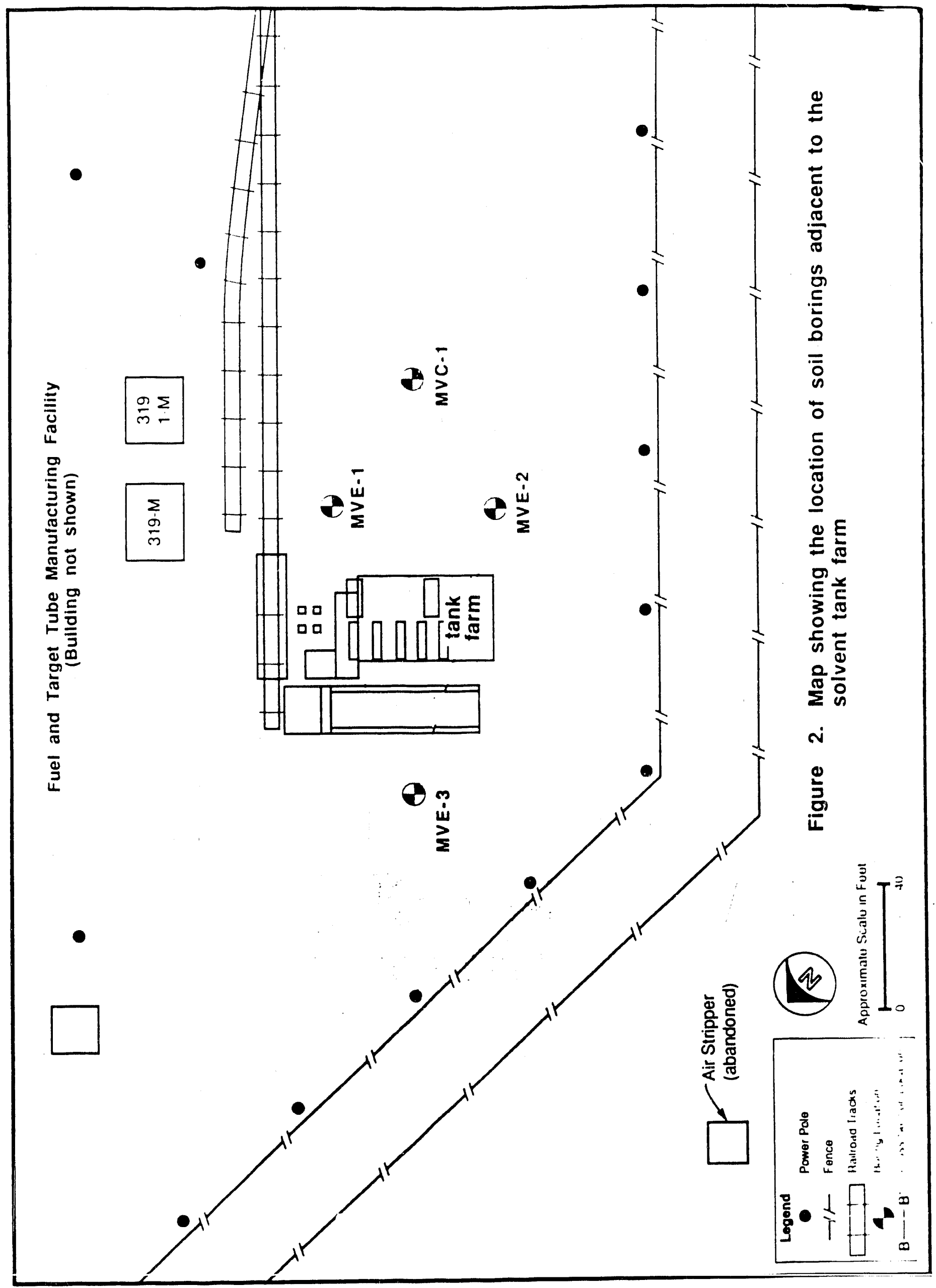


$\mathrm{C}$ for later analysis at an onsite laboratory. The subsample corer (syringe) was decontaminated between sampling events by brushing and rinsing with isopropanol followed by a distilled water wash.

\section{Modified E.P.A. Sampling Procedure}

Adjacent to the headspace subsample collection point, a subcontractor immediately collected an aliquot of sediment from the open split-spoon using a stainless steel spatula and packed it into a 2-ounce borosilicate jar with a teflon-lined screw cap. The jar was labeled and placed in an ice chest cooled to approximately $4^{\circ} \mathrm{C}$ for later analysis by the Close Support Laboratory (CSL). The stainless steel spatula was decontaminated between sampling events by wiping with a disposable moist Towelette.

\section{Laboratory Analysis Procedure}

The two separate laboratories utilized in the study to analyze the sediment subsamples were an onsite laboratory operated by Savannah River Laboratory personnel and a CSL operated by independent subcontract personnel. The onsite laboratory analyzed the headspace sediment subsamples and the CSL analyzed the sediment subsamples collected by the independent subcontractor. Both laboratories used standard Chain of Custody procedures and collected Quality Assurance/Quality Control (QA/QC) sediment subsamples to comply with the Savannah River Site Quality Assurance Requirements. These requirements included the analysis of duplicate samples, matrix spikes, and trip blanks at a minimum of ten percent of the total number of samples. All analyses were performed within the required holding time.

\section{Headspace Analysis Procedure}

The onsite laboratory consisted of a headspace analyzer connected to a Hewlett Packard 5890A Gas Chromatograph (GC). The headspace analysis procedure used is given below.

Step 1. Prior to field sampling, determine the average weight of a sealed headspace vial containing $5 \mathrm{~mL}$ of water. Upon receipt of the headspace sample vials from the field, weigh the capped vial containing the sediment sample. Subtract the weight of the vial without the sediment from the vial containing the sediment to determine the amount of sediment in the sample vial.

Step 2. Placed vial with the sediment subsample in the headspace analyzer for analysis. Download the GC results from each sample analyzed into a computer for interpretation.

A previous study was conducted by Savannah River Laboratory personnel in order to evaluate the effects of adding a sodium sulfate/phosphoric acid solution instead of distilled water to the headspace sediment sample. The results of this study indicated that there was a significant statistical difference between the VOC analysis using distilled water versus the sodium sulfate/phosphoric acid solution. The use of distilled water in the headspace vial increased the volatilization and measured concentration of VOC. Additional work was conducted to determine whether sonication of the sample increased the measured VOC concentration. The results indicated that there was not a significant statistical difference between the samples that were sonicated for 15 minutes and the samples that were not sonicated. 


\section{Subcontractor Modified EPA 3550 Analysis Procedure}

The CSL consisted of a travel camper outfitted with a Hewlett Packard 5890A gas chromatograph, electron capture detector, and an ultrasonic sonicator. Additional equipment included a balance, an oven for drying samples, a computer with printer and laboratory/safety supplies. The CSL was operated on a daily basis during the sediment boring investigation to provide analytical results on a real-time basis. The results were used to determine screen intervals for the vapor extraction wells installed as part of a vadose zone remediation program in M-Area.

The CSL analytical method used pentane in conjunction with sonication to extract the target constituents (predominantly PCE) from the sediment matrix. The method was based on EPA Method 3550, Sonication Extraction, found in EPA SW 846, "Test Methods for Evaluating Solid Wastes", 3rd ed., November 1986. The modified EPA Method 3550 procedure for sample preparation and extraction is included below.

Step 1. In a labeled VOA vial $(40 \mathrm{~mL})$, volumetrically pipet $5 \mathrm{~mL}$ of pentane and record the volume added. Place the vial on the top loading balance and record its tare weight. Add an aliquot of sediment from the 2-ounce jar subsample (approximately 5 to 10 grams) to the vial and accurately record the sample weight to the nearest 0.01 grams.

Step 2. If the sample is wet or highly consolidated (i.e. clay), add approximately 2 grams of sodium sulfate and mix.

Step 3. Tightly cap the VOA vial and sonicate at an output setting of 30 percent for approximately 5 minutes. The resulting sonicated sample should be dispersed throughout the pentane solvent and have a grain-like appearance. If not, then add an additional 1 gram of sodium sulfate and sonicate. Repetitions of this process may be needed to complete the extraction from some samples.

Siep 4. After sonication, let the VOA vial stand until the solids have settled. Using a pasteur pipet, transfer a suitable aliquot of the pentane solvent (extract) from the vial in a labeled GC auto-sampler vial and cap immediately with septum crimp seals. Refrigerate the sample extracts until analyzed.

Step 5. After the sample was prepared, the extract was injected into a Hewlett Packard 5890A GC with an electron capture device for analysis.

\section{DISCUSSION}

The results of the laboratory analyses for the headspace method and the subcontractor modified EPA 3550 Method are presented in Tables 1 and 2. A total of 92 sediment subsamples were analyzed for this study. In addition, 16 duplicate headspace sediment subsamples were collected to determine reproducibility of the analytical data. The concentrations of TCE and PCE in the headspace sediment subsamples ranged from less than $1 \mathrm{ng} / \mathrm{g}$ (presented as 1 on the Table 1 and 2), up to 14,583 and $91,670 \mathrm{ng} / \mathrm{g}$ respectively. The concentrations of TCE and PCE in the sediment subsamples utilizing the subcontractor modified analytical method ranged from less than $1 \mathrm{ng} / \mathrm{g}$ up to 1,016 and $2,620,000 \mathrm{ng} / \mathrm{g}$ respectively. The duplicate samples, trip blanks, matrix spikes, and matrix 
Table 1

SOIL BORING MVE-1

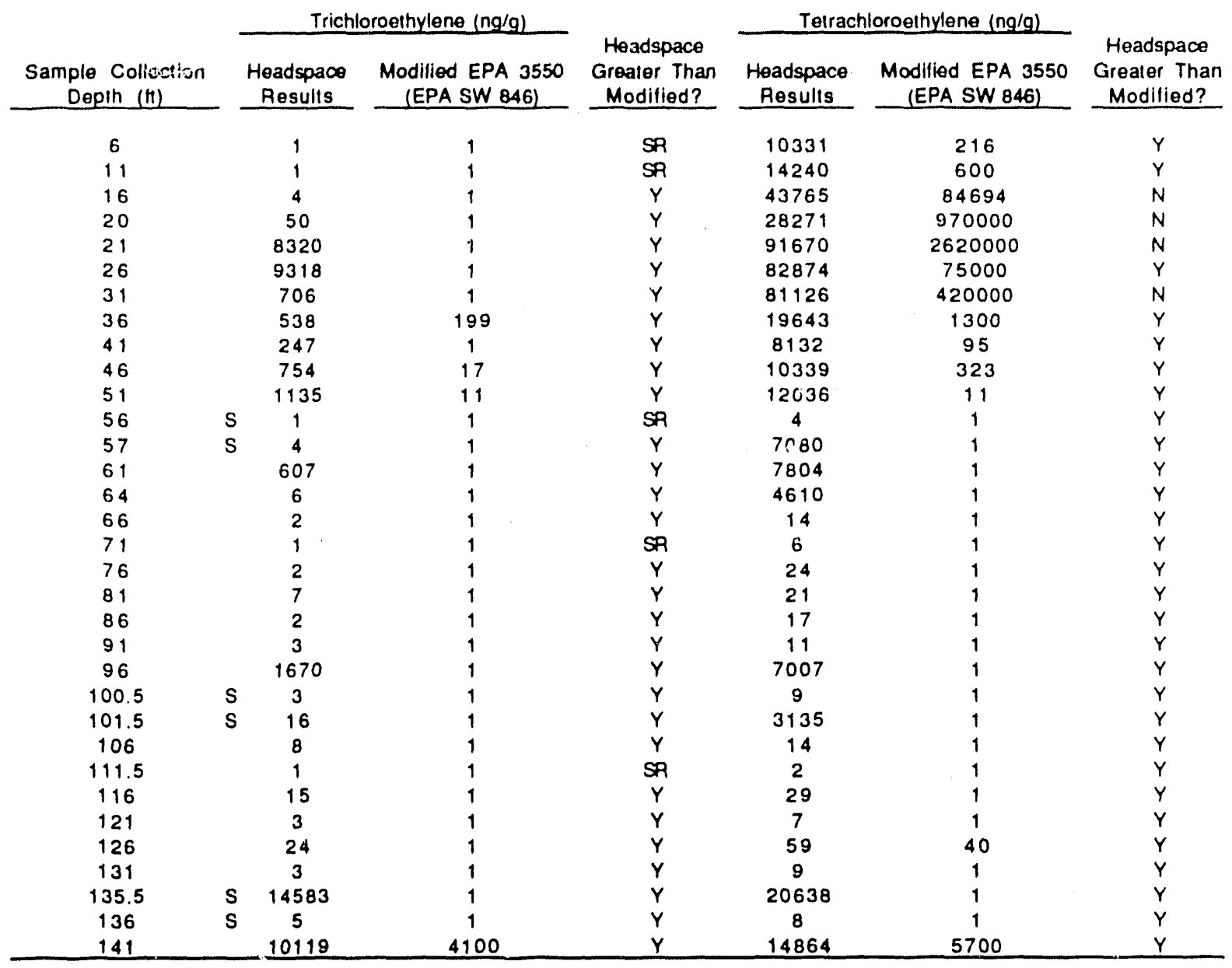

SOIL BOAING INE-3*

\begin{tabular}{|c|c|c|c|c|c|c|}
\hline 21 & 3 & 2 & $\bar{Y}$ & 3 & 1 & $\bar{Y}$ \\
\hline 31 & 327 & 9 & $Y$ & 7726 & 1 & $Y$ \\
\hline 36 & 204 & 7 & $Y$ & 27 & 15 & $Y$ \\
\hline 46 & 444 & 3 & $Y$ & 2684 & 10 & $Y$ \\
\hline 56 & 2147 & 3 & $Y$ & 3694 & 11 & $Y$ \\
\hline
\end{tabular}

$Y=Y e s$

$N=N_{0}$

$\mathrm{SR}=$ Same Result

- = Soll Boring Partialty Sampled

$D=$ Average of Duplicare Headspace Anahyses

$S=$ Two Subsamples Collected From One Split-Spoon Core 
Table 2

SOIL BOAING MVC-1

\begin{tabular}{|c|c|c|c|c|c|c|c|}
\hline \multirow[b]{2}{*}{$\begin{array}{c}\text { Sample Collection } \\
\text { Depin (ti) }\end{array}$} & \multicolumn{3}{|c|}{ Trichloroethylene $(\mathrm{ng} / \mathrm{g})$} & \multirow[b]{2}{*}{$\begin{array}{l}\text { Headspace } \\
\text { Greater Than } \\
\text { Modillied? }\end{array}$} & \multicolumn{2}{|c|}{ Telrachloroethylene $(\mathrm{ng} / \mathrm{g})$} & \multirow[b]{2}{*}{$\begin{array}{c}\text { Headspace } \\
\text { Grealer Thar } \\
\text { Modifled? }\end{array}$} \\
\hline & & $\begin{array}{l}\text { Headspace } \\
\text { Results }\end{array}$ & $\begin{array}{c}\text { Modilied EPA } 3550 \\
\text { (EPA SW 846) } \\
\end{array}$ & & $\begin{array}{c}\text { Headspace } \\
\text { Resulls } \\
\end{array}$ & $\begin{array}{l}\text { Modilied EPA } 3550 \\
\text { (EPA SW 846) } \\
\end{array}$ & \\
\hline 6 & & 1 & 1 & SA & 1 & 1 & SR \\
\hline 11 & & 1 & 1 & SR & 1 & 1 & $S R$ \\
\hline 16 & & 1 & 1 & $\mathbf{S R}$ & 14 & 1 & Y \\
\hline 21 & & 1 & 1 & SR & 2 & 1 & $Y$ \\
\hline 26 & & 1 & 1 & SA & 3 & 1 & Y \\
\hline 36 & & 10 & 1 & $Y$ & 19 & 1 & $Y$ \\
\hline 41 & & 149 & 1 & $Y$ & 5376 & 1 & $Y$ \\
\hline 46 & & 14 & 1 & $Y$ & 31 & 1 & Y \\
\hline 51 & & 1 & 1 & SR & 1 & 1 & SR \\
\hline 56 & & 1 & 1 & SR & 1 & 1 & SR \\
\hline 65 & $\mathrm{~S}$ & 1 & 1 & SR & 1 & 1 & SR \\
\hline 66 & S & 2 & 1 & $Y$ & 5 & 1 & $Y$ \\
\hline 71 & & 1 & 1 & SR & 2 & 1 & $Y$ \\
\hline 76 & & 1 & 1 & $S R$ & 1 & 1 & $S R$ \\
\hline 81 & & 1 & 1 & 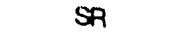 & 3 & 1 & Y \\
\hline 86 & & 3 & 1 & $Y$ & 8 & 1 & $Y$ \\
\hline 91 & & 16 & 1 & Y & 62 & 1 & Y \\
\hline 100 & & 6621 & 33 & $Y$ & 13892 & 35 & $Y$ \\
\hline 101 & & 8 & 1 & Y & 17 & 1 & $Y$ \\
\hline 105 & $\mathrm{~s}$ & 544 & 1 & $Y$ & 5170 & 1 & $Y$ \\
\hline 106 & $\mathbf{S}$ & 1 & 1 & SR & 2 & 1 & $Y$ \\
\hline 111 & & 1513 & 362 & $Y$ & 8569 & 119 & $Y$ \\
\hline 116 & & 4920 & 1 & Y & 8768 & 87 & $Y$ \\
\hline 121 & & 4 & 1 & Y & 6 & 1 & $Y$ \\
\hline 126 & & 13 & 1 & Y & 20 & 9 & $Y$ \\
\hline 131 & & 15 & 1 & $Y$ & 28 & 1 & $Y$ \\
\hline
\end{tabular}

SOIL BORING MVE-2

\begin{tabular}{|c|c|c|c|c|c|c|c|}
\hline 6 & & 2 & 1 & $\bar{Y}$ & 9 & 16 & $N$ \\
\hline 11 & & 2 & 1 & $Y$ & 9 & 9 & SR \\
\hline 16 & & 3 & 1 & $Y$ & 30 & 1 & $Y$ \\
\hline 21 & $D$ & 2 & 1 & $Y$ & 2594 & 11 & $Y$ \\
\hline 26 & & 80 & 3 & $Y$ & 4667 & 31 & $Y$ \\
\hline 31 & $D$ & 27 & 2 & $Y$ & 3135 & 14 & $Y$ \\
\hline 36 & & 32 & 5 & $Y$ & 3312 & 33 & $Y$ \\
\hline 41 & $D$ & 35 & 2 & $Y$ & 3531 & 12 & $Y$ \\
\hline 46 & $D$ & 68 & 5 & $Y$ & 3332 & 36 & $Y$ \\
\hline 51 & & 206 & 5 & $Y$ & 4321 & 33 & $Y$ \\
\hline 56 & 0 & 5 & 7 & $\mathbf{N}$ & 5 & 34 & $\mathbf{N}$ \\
\hline 61 & $D$ & 266 & 5 & $\ddot{Y}$ & 5189 & 27 & $Y$ \\
\hline 66 & & 2 & 2 & $\mathbf{S R}$ & 4 & 10 & $\mathbf{N}$ \\
\hline 71 & $D$ & 10 & 1 & $Y$ & 13 & 1 & : \\
\hline 76 & & 1 & i & SR & 1 & 1 & SR \\
\hline 81 & $D$ & 1 & 2 & $\mathbf{N}$ & 1 & 12 & $N$ \\
\hline 86 & & 1 & 1 & $\mathbf{s R}$ & 3 & 1 & $\because$ \\
\hline 91 & D & 1 & 1 & $\mathbf{S A}$ & 3 & 1 & $Y$ \\
\hline 96 & & 4 & 558 & $N$ & 3397 & 668 & $Y$ \\
\hline 101 & D & 7 & 2 & $Y$ & 16 & 8 & $Y$ \\
\hline 106 & D & 21 & 3 & $Y$ & 1711 & 17 & $Y$ \\
\hline 111 & D & 1 & 2 & $\mathbf{N}$ & 2 & 11 & $N$ \\
\hline 116 & $D$ & 9 & 14 & $N$ & 19 & 44 & N \\
\hline 121 & & 1 & 6 & $\mathbf{N}$ & 4 & 20 & $N$ \\
\hline 126 & $D$ & 2 & 14 & $N$ & 3 & 41 & $N$ \\
\hline 131 & 0 & 3 & 78 & $\mathbf{N}$ & 5 & 92 & $\mathbf{N}$ \\
\hline 136 & D & 7551 & 1016 & $Y$ & 9361 & 706 & $Y$ \\
\hline
\end{tabular}


spike duplicates performed for the methods indicated that both methods could adequately measure the contaminants at concentrations down to the detection limit and that both methods generated reproducible results.

In general, the headspace analysis method resulted in a higher value for the measured concentration of both TCE and PCE (Table 3). The primary exceptions to this general trend are: 1) samples with very high concentrations of contaminants, and 2) samples where both methods were below detection. Fol example, in soil boring MVE-1, there are five instances where the two methods are the same for TCE -- all of these in tances result from below detection results from both methods. Similarly, in this core, the results frorn the rnodified EPA method are greater four out of thirty-three times -- all four instances result from truncation of very high concentrations inherent in the headspace method. These same trends may be observed in all of the other cores. The paired data used to generate Table 3 were ranked and ordered for statistical analysis. In this form, a Wilcoxon Signed Rank Test was applied to determine if the two methods yield statistically different results. This test is used when the shape of the underlying distribution is unknown to test the hypothesis that two population distributions are identical. At the $90 \%$ confidence interval, this hypothesis was rejected signifying that the two populations are different. Thus, the statistical test indicated that there is greater than a $99 \%$ probability that the two methods are statistically different (i.e., the headspace method generates higher values).

Table 4 provides detailed information on depth, PCE concentrations, and lithology for MVE-1. Results from this core illustrate the relationship between concentration and lithology, and reinforce the general conclusions discussed above. The headspace method indicated the presence of contamination in each of the silty, clayey and poorly graded layers throughout thie core. The modified EPA method generated below detection results for most of these zones. The headspace method truncated a series of very high concentrations in the upper part of the core. Figure 3 is a graphical representation of the data. The headspace method indicates low (but measurable) concentrations in the well graded sands, while the modified EPA method indicates below detection results in almost all of these layers.

From an analytical standpnint, there are several advantages of the headspace method over the subcontractor modified EPA Method. Some of these advantages include: 1) reduced sample handling effort and time in the field, 2) no solvent extraction required (the Henry's Law mass transfer in the headspace vial requires no operator effort), and 3) elimination of multiple sample transfers and minimization of the opportunities for volatilization of analyte. The headspace sediment sample is sealed in its final form ready for analysis within a few seconds of collection and is never directly handled again during weighings or transfers. Once in the laboratory, approximately 50 samples can be analyzed in a normal working day on a single instrument. This allow'; data to be rapidly transmitted back to the field for incorporation into decisions about the drilling and characterization operations.

\section{CONCLUSION}

Despite the precautions incorporated into the modified EPA method, the analytical results indicate that sample transfers in the field and laboratory resulted in volatilization of most of the volatile solvents in the sediment samples. The headspace method appears to provide more representative data on the samples. One limitation of the headspace method is that the sample can not be diluted; thus, very high concentrations are truncated by an upper limit of detection. In most cases, this truncation may not be of practical significance $b$ scause it 


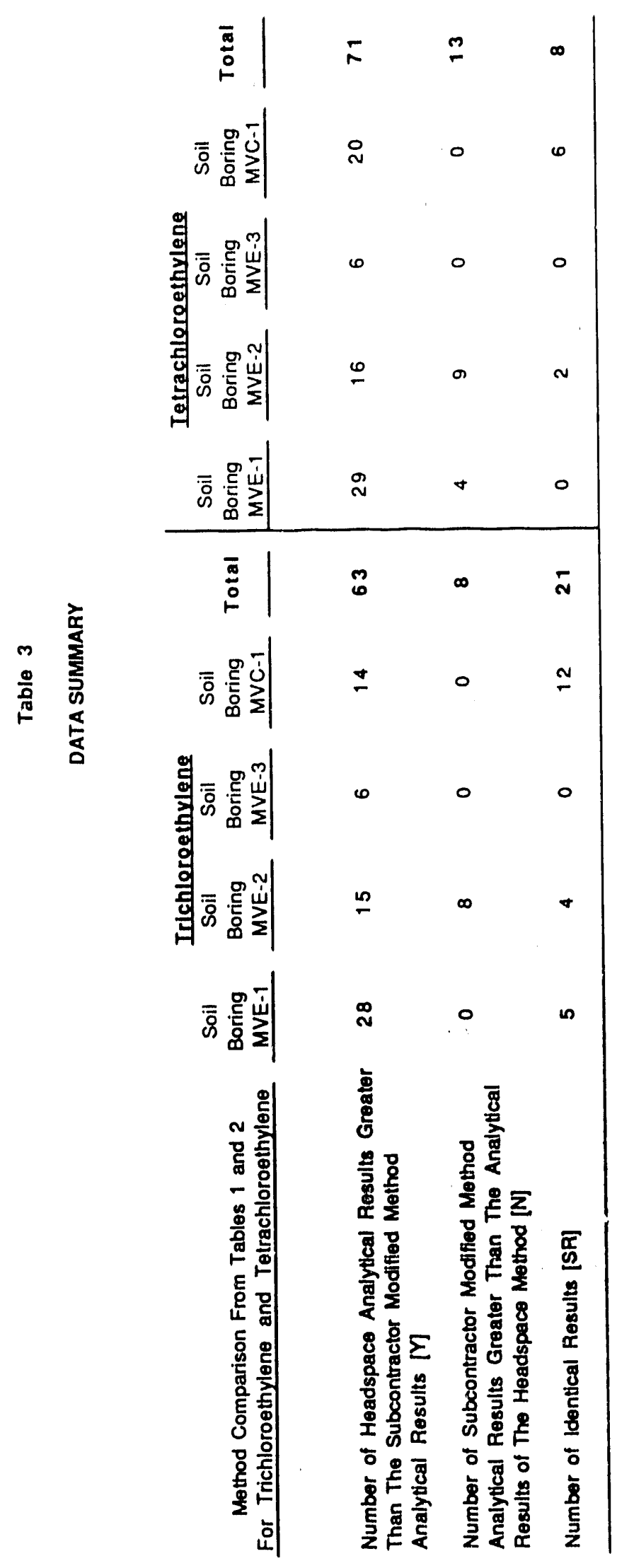


PCE CONCENTRATIONS VERSUS LTHOLOGY IN SOIL BORING MVE-1

\begin{tabular}{|c|c|c|c|c|}
\hline \multirow{2}{*}{$\begin{array}{l}\text { Sample Collection } \\
\text { Depth (tt) }\end{array}$} & \multicolumn{3}{|c|}{ Tetrachloroethylene $(\mathrm{ng} / \mathrm{g})$} & \multirow[b]{2}{*}{$\begin{array}{l}\text { Abbreviated Field Lithologlo } \\
\text { Description of the Split Spoon Core }\end{array}$} \\
\hline & & $\begin{array}{l}\text { Headspace } \\
\text { Results } \\
\end{array}$ & $\begin{array}{l}\text { Modified EPA } 3550 \\
\text { (EPA SW 846) } \\
\end{array}$ & \\
\hline 6 & & 10331 & 216 & SANDY SILT (ML), dense, $5 \%$ clay \\
\hline 11 & & 14240 & 600 & SANDY SILT (ML), dense, $5 \%$ clay \\
\hline 16 & & 43765 & 84694 & SILTY SAND (SM), very dense, $10.15 \%$ clay \\
\hline 20 & S & 28271 & 970000 & SILTY SAND (SM), very dense, $10.15 \%$ clay \\
\hline 21 & S & 91670 & 2620000 & SILTY SAND (SM), very dense, $10 \cdot 15 \%$ clay \\
\hline 26 & & 82874 & 75000 & SILTY SAND (SM), very dense, $10-15 \%$ clay, clayey lenses \\
\hline 31 & & 81126 & 420000 & CLAYEY SAND (SC) \\
\hline 36 & & 19643 & 1300 & POORLY GRADED SAND WITH SILT (SP.SM) \\
\hline 41 & & 8132 & 95 & POORLY GFIADED SAND WITH SILT (SP.SM) \\
\hline 46 & & 10339 & 323 & SILTY SAND (SM) \\
\hline 51 & & 12036 & 11 & SILTY SAND (SM) \\
\hline 56 & S & 4 & 1 & WELL GRADED SAND (SW) \\
\hline 57 & S & 7080 & 1 & POORLY GRADED SAND (SP) \\
\hline 61 & & 7804 & 1 & POORLY GRADED SAND (SP), clay lenses \\
\hline 64 & S & 4610 & 1 & SILTY SAND (SM), clay lenses \\
\hline 66 & S & 14 & 1 & WELL GRADED SAND (SW) \\
\hline 71 & & 6 & 1 & WELL GRADED SAND (SW) \\
\hline 76 & & 24 & 1 & WEL GRADED SAND (SW) \\
\hline 81 & & 21 & 1 & WEL GRADED SANO (SW) \\
\hline 86 & & 17 & 1 & WELL GRADED SAND (SW) \\
\hline 91 & & 11 & 1 & WELL GRADED SAND (SW) \\
\hline 96 & & 7007 & 1 & WELL GRADED SAND WITH CLAY (SW-SC) \\
\hline 100.5 & S & 9 & 1 & WEL GRADED SAND (SW) \\
\hline 101.5 & s & 3135 & 1 & WELL GRADED SAND WITH CLAY (SW-SC) \\
\hline 106 & & 14 & 1 & WELL GRADED SAND (SW) \\
\hline 111.5 & & 2 & 1 & WELL GRADED SAND (SW), thin clay stringers (white) \\
\hline 116 & & 29 & 1 & WE:LL GRADED SAND (SW), thin clay stringers (white) \\
\hline 121 & & 7 & 1 & WEU GRADED SAND (SW) \\
\hline 126 & & 59 & 40 & WELL GRADED SAND (SW), some gravel \\
\hline 131 & & 9 & 1 & WELL GRADED SAND (SW), some gravel \\
\hline 135.5 & S & 20638 & 1 & POORLY GRADED SAND WITH CLAY (SP-SC), 2 mm day Ins. \\
\hline 136 & S & 8 & 1 & WELL GRADED SAND (SN \\
\hline 141 & & 14864 & 5700 & WELL GRADED SAND (SW), Moist, Top of the Water Table \\
\hline
\end{tabular}

$\mathbf{S}=$ Two Subsamples Collected From One Split-Spoon Core 
Figure 3.

VERTICAL PROFILE OF PCE CONCENTRATIONS FROM THE TWO

ANALYTICAL METHODS

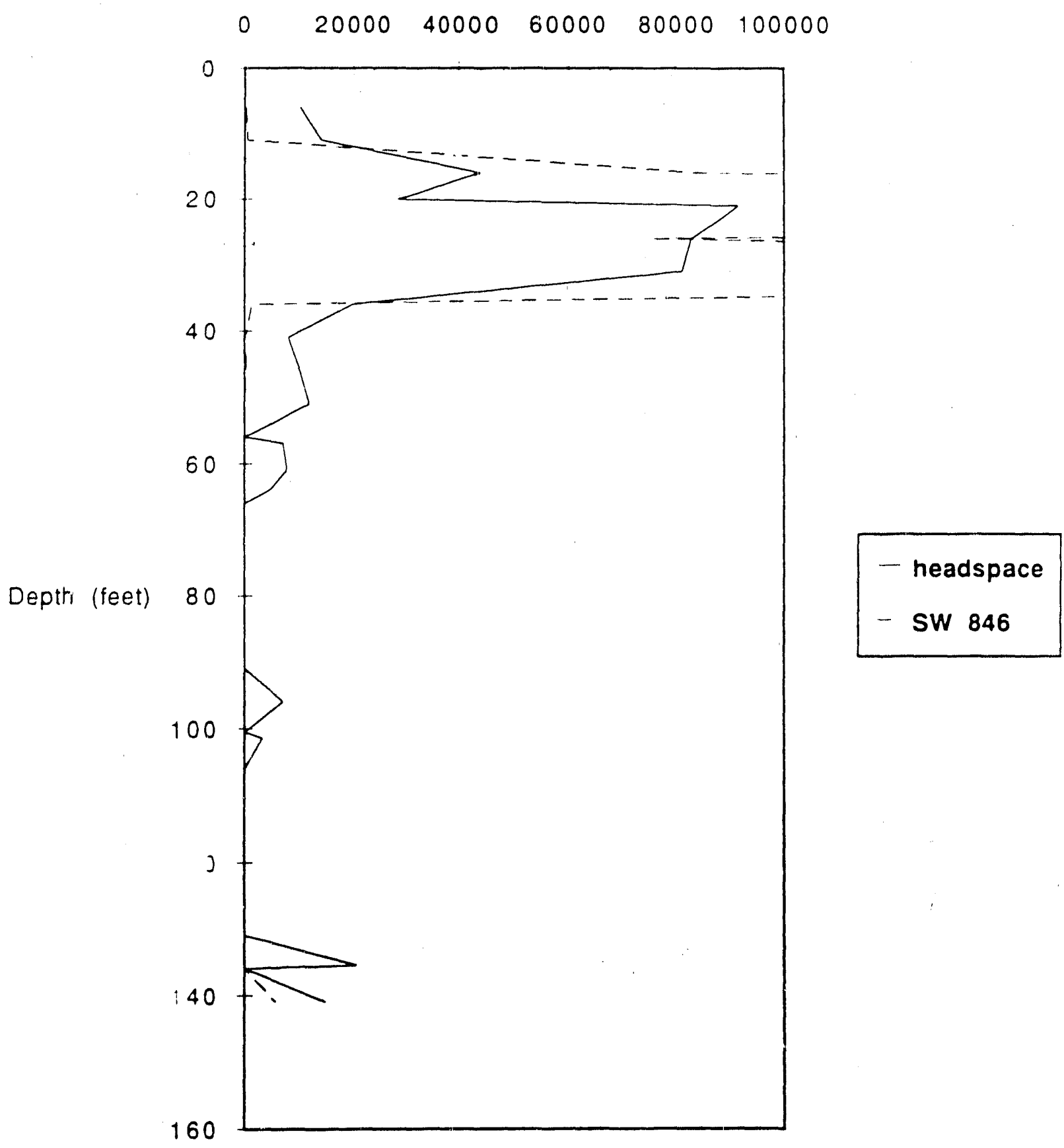

Tetrachloroethylene Concentrations (ng/g) 
occurs at relatively high concentrations (e.g., 100,000 ng/g). The results indicate that the headspace method minimized loss of volatiles associated with sample handling and provided large amounts of closely spaced data in a cost effective manner. The headspace results can be generated rapidly and transferred to the field such that informed decisions can be made during site characterization.

\section{REFERENCES}

U. S. Environmental Protection Agency, 1986. Test Methods for Evaluating Solid Waste, Physical/Chemical Methods. S $\mathrm{W}$-846. Office of Solid Waste and Emergency Response, Washington, D. C.

\section{ACKNOWLEDGEMENTS}

The information contained in this article was developed during the course of work under Contract No. DE-AC09-89SR18035 with the U. S. Department of Energy. 


\section{BIOGRAPHICAL SKETCHES}

W. R. Sims received his MS degree in Geology from the University of Akron in 1987. He is currently a hydrogeologist in the Environmental Restoration Department at the Savannah River Site. His responsibilities and interests include RCRA/CERCLA waste site assessments, vadose zone and groundwater characterization and remediation, and regulatory support for groundwater corrective actions. Westinghouse Savannah River Company, P. O. Box 616 (Merrill Lynch Building), Aiken SC 29808. (404)-821-7962

B. B. Looney received his $\mathrm{PhD}$ in Environmental Engineering from the University of Minnesota in 1983. He is currently employed as a research engineer in the Savannah River Laboratory and is an adjunct professor in the Environmental Systems Engineering Program at Clemson University. His interests and responsibilities include, developing and testing new methods for environmental characterization and remediation, risk assessment, and modeling. Westinghouse Savannah River Company, 773-42A, Aiken SC 29808. (803)725-5189

C. A. Eddy is completing her $\mathrm{PhD}$ in geology at University of California,Davis. She is currently employed as a research geologist at the Savannah River Laboratory. Her interests include geulogy ind analytical geochemistry. Westinghouse Savannah River Company, 773-42A, Aiken iSC 29808. (803)-725-2418 

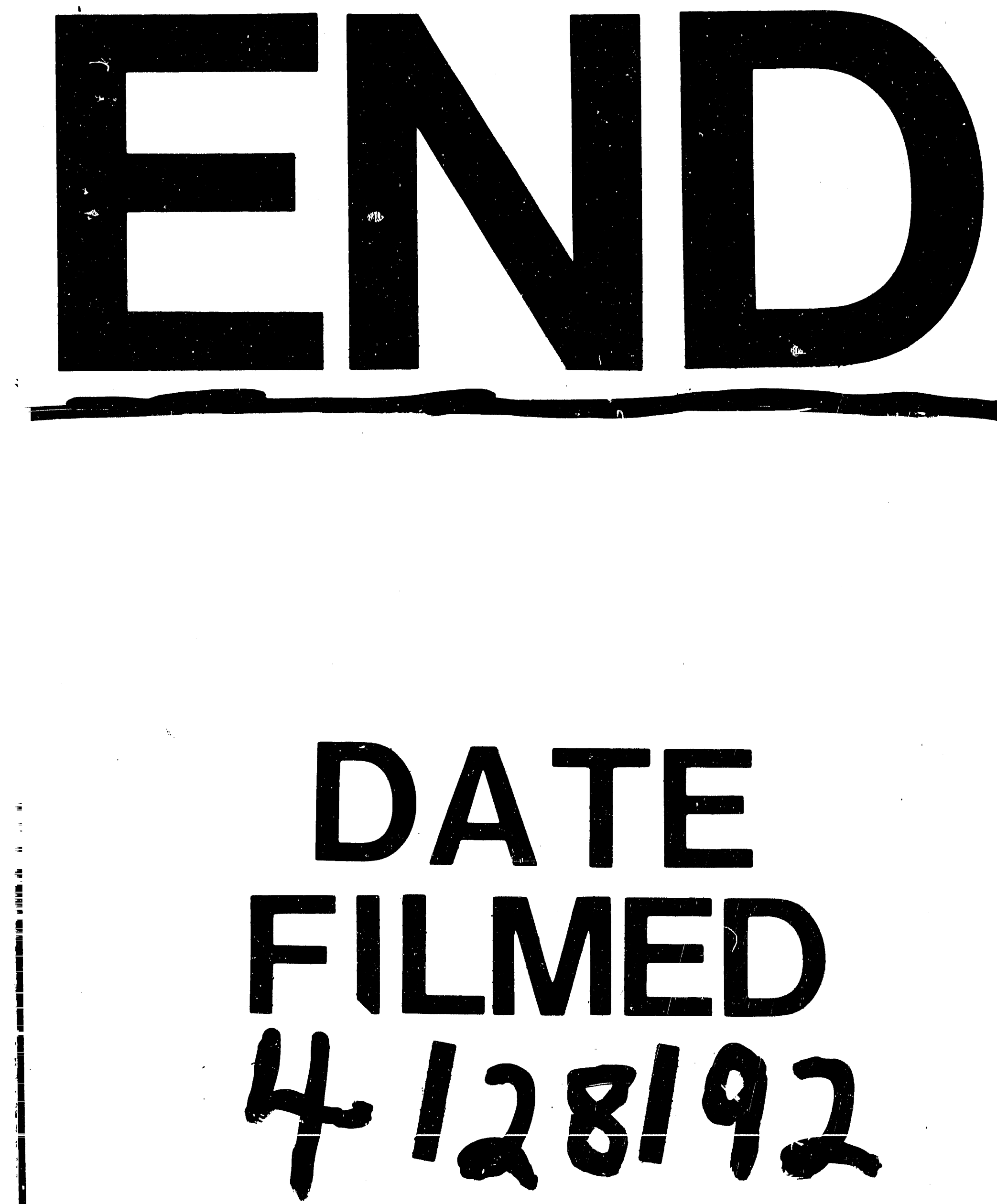

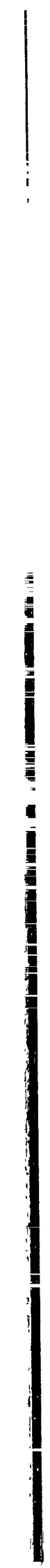